Article

\title{
Effect of the Initial Texture, Recrystallization and Re-Dissolution Process on the Evolution of Texture during Solution Treatment of the 7A65 Hot Rolled Plate
}

\author{
Hao Wang ${ }^{1,2}$, Lina Jia ${ }^{1,2, *}$, Wenbo Wang ${ }^{2}$, Chengtong Ye ${ }^{1,2}$, Chen ${ }^{3}$, Xinquan Zhang ${ }^{3}$ and $\mathrm{Hu} \mathrm{Zhang}^{1,2, *}$ \\ 1 Department of Materials Science and Engineering, Beihang University, Beijing 100191, China; \\ wh1244579992@buaa.edu.cn (H.W.); yct209@buaa.edu.cn (C.Y.) \\ 2 Research Center for Lightweight Materials, Ningbo Institute of Technology, Beihang University, \\ Ningbo 315100, China; wenbowang@buaa.edu.cn \\ 3 The First Aircraft of Institute of AVIC, Xi'an 710089, China; lichen_1983_2002@163.com (C.L.); \\ xinquan417@126.com (X.Z.) \\ * Correspondence: jialina@buaa.edu.cn (L.J.); zhanghu@buaa.edu.cn (H.Z.)
}

Citation: Wang, H.; Jia, L.; Wang, W.; Ye, C.; Li, C.; Zhang, X.; Zhang, H.

Effect of the Initial Texture,

Recrystallization and Re-Dissolution Process on the Evolution of Texture during Solution Treatment of the 7A65 Hot Rolled Plate. Metals 2022, 12, 8. https://doi.org/10.3390/ met12010008

Academic Editors: Angelo

Fernando Padilha and

Junsheng Wang

Received: 24 November 2021

Accepted: 18 December 2021

Published: 21 December 2021

Publisher's Note: MDPI stays neutral with regard to jurisdictional claims in published maps and institutional affiliations.

Copyright: (C) 2021 by the authors. Licensee MDPI, Basel, Switzerland. This article is an open access article distributed under the terms and conditions of the Creative Commons Attribution (CC BY) license (https:// creativecommons.org/licenses/by/ $4.0 /)$.

\begin{abstract}
The evolution of textures, the degree of recrystallization and the mechanical properties of 7A65 hot rolled plates during re-dissolution were studied with different thicknesses $(25 \mathrm{~mm}$, $65 \mathrm{~mm}, 120 \mathrm{~mm}$ ) and different degrees of deformation. It was found that different plates exhibited different trends of re-dissolution because the degrees of deformation increased and the degrees of recrystallization were different during the solution treatment. With the increase of deformation and static recrystallization degrees, texture types changed from Cube, R-Cube to Brass, R, Cube and Copper during the re-dissolution process. The value of the Schmid factor $(\bar{\mu})$ was calculated and the value along the rolling direction was significantly larger than along the transverse direction, which led to a lower yield strength along the rolling direction. In terms of the average contribution of the yield strength, the strengthening of the grain boundary including LAGBs (low-angle grain boundaries) was found to play a more significant role than the effect of solid atoms and dislocation densities. Therefore, the $25 \mathrm{~mm}$ plate exhibits the best mechanical properties, with a yield strength of $565.7 \mathrm{MPa}$ along the rolling direction.
\end{abstract}

Keywords: 7A65 hot rolled plates; re-dissolution; recrystallization; texture evolution; Schmid factor

\section{Introduction}

In the field of aeronautical materials, especially in the aircraft manufacturing field, $\mathrm{Al}-\mathrm{Zn}-\mathrm{Mg}-\mathrm{Cu}$ hot rolled plates with different heat treatment conditions have been used extensively in recent years [1,2]. Nonetheless, mechanical anisotropy is often a problem that exists in hot rolled plates [3-6]. Different plates with different degrees of deformation exhibit contrasting extents of mechanical anisotropy [7-11]. Texture type and orientation density are the main factors that affect mechanical anisotropy, and texture evolution will occur in the process of solution treatment [12-15]. Thus, it is crucial to observe the relationship between the texture and mechanical anisotropy in different solid solution stages [16-19].

Owing to the deformation of the plates differing greatly, the initial textures and degrees of recrystallization are different which leads the evolution process to be slightly different [20-24]. Han et al. [25] investigated the effect of the initial texture on dissimilar channel angular pressing (DCAP). The results showed that the $<110>/ / \mathrm{ND}$ (the normal direction) texture accelerated the formation of the $<111>/ / N D$, and the Cube texture accelerated the formation of R-Cube. In the previous investigations of the solution process, different solution treatments affected texture evolution to different degrees [26,27]. However, almost no research has focused on the influence of the initial texture of the hot rolled plates during the solution process at the same solution temperature. Thus, this subject is certainly interesting and important. 
In addition to considering the effect of initial texture and recrystallization, the influence of the re-dissolution should be investigated as well. The reason is that the solution process is complex and involves a mass of changes including re-dissolution of the second phase, recrystallization and texture evolution $[16,18]$. Thus, it is of great significance to analyze the whole re-dissolution process and observe the relationship among re-dissolution, recrystallization and texture evolution. Diffusion is the main factor that affects the re-dissolution process, and temperature and defect density are the two factors that influence the diffusion process [28]. Thus, due to the plates having different deformation, the defect density is different and there are contrasts in the diffusion process during solution treatment, which may affect texture evolution in the following solution treatment. In this research, the re-dissolution process was studied and the evolution of textures was discussed to clarify the effects of the initial texture, recrystallization and the re-dissolution process on texture evolution for plates of different thickness. Mechanical properties and anisotropy after different solution treatments were also found to be related to the texture and the degree of recrystallization.

\section{Materials and Methods}

Different thicknesses $(25 \mathrm{~mm}, 65 \mathrm{~mm}, 120 \mathrm{~mm})$ of 7A65 hot rolled plates with a nominal composition of Al-7.7Zn-1.65 Mg-1Cu-0.1Zr were selected for the experiment. To examine the evolution trends of re-dissolution and orientation density with the extension of solution time, samples were taken from the center thickness of the plates. The solid solution temperature in this study was $477^{\circ} \mathrm{C} ; 30 \mathrm{~min}, 90 \mathrm{~min}, 210 \mathrm{~min}$ and $330 \mathrm{~min}$ were adopted as the solution times in this study. In order to eliminate the impacts of the quenching sensitivity, samples were tested in the same size. Samples $(75 \mathrm{~mm} \times 60 \mathrm{~mm} \times 25 \mathrm{~mm}$ ) were cut from the plates continuously and then the solid solution treatment was conducted in the box furnace. After water quenching at room temperature, the same $\mathrm{T} 74\left(121^{\circ} \mathrm{C} / 6 \mathrm{~h}+\right.$ $152{ }^{\circ} \mathrm{C} / 25 \mathrm{~h}$ ) ageing treatment was accomplished for all the samples.

Optical microscopy (OM) images were obtained after the samples were etched with Keller reagent. The scanning electron microscope (SEM) was applied to observe the phase morphology and distribution, and energy dispersive spectroscopy (EDS) was adopted to confirm the phase composition. Samples for electron backscatter diffraction (EBSD) were prepared after being mechanically polished and electrolytically polished. The grain orientation and the percentage of low-angle grain boundaries (LAGBs) and high angle grain boundaries (HAGBs) were identified by using EBSD results after being analyzed by TSL OIM Analysis software (version 5.3, EDAX, Beijing, China). The Schulz back reflection method was adopted to perform the macro texture tests using X-ray diffraction (XRD), and the results were processed by the JTEX software (developed by J.-J. Fundenberger and B. Beausir) to obtain the orientation distribution function (ODF) and the inverse pole figure (IPF) results. The orientation densities of all textures were obtained through picture scales, after gathering statistics. Meanwhile, the volume fraction of Brass texture was obtained through calculating the proportion of Brass orientation density in all orientation densities. Samples for texture and conductivity tests $(10 \mathrm{~mm} \times 10 \mathrm{~mm} \times 10 \mathrm{~mm})$ were cut after solution treatment and the surface of rolling was tested. Conductivity tests were performed using an eddy current conductivity meter, and the mean of five test results was considered the final result. Conductivity was measured to analyze the degree of second phase re-dissolution. Tensile tests were performed along the rolling direction (RD) and the transverse direction (TD) to analyze the relationship between the mechanical properties and the texture (including the types and orientation density).

\section{Results}

\subsection{Microstructure of Hot Rolled Plates}

Figure 1 shows the grain structure and the phase composition of the hot rolled plates. The degree of grain deformation of the $25 \mathrm{~mm}$ hot rolled plate is greater than that of the $65 \mathrm{~mm}$ plate. The same shifting trend can be observed in the experiments with the $120 \mathrm{~mm}$ 
hot rolled plate. The phase composition does not change significantly in the microstructure of the $25 \mathrm{~mm}$ and $65 \mathrm{~mm}$ plate compared with the $120 \mathrm{~mm}$ plate. The phenomenon that the $\mathrm{Al}_{7} \mathrm{Cu}_{2} \mathrm{Fe}$ phase distributes along the grain boundaries can be observed in the microstructure of the $25 \mathrm{~mm}$ and $65 \mathrm{~mm}$ plates, which is similar to the microstructure of the $120 \mathrm{~mm}$ plate.
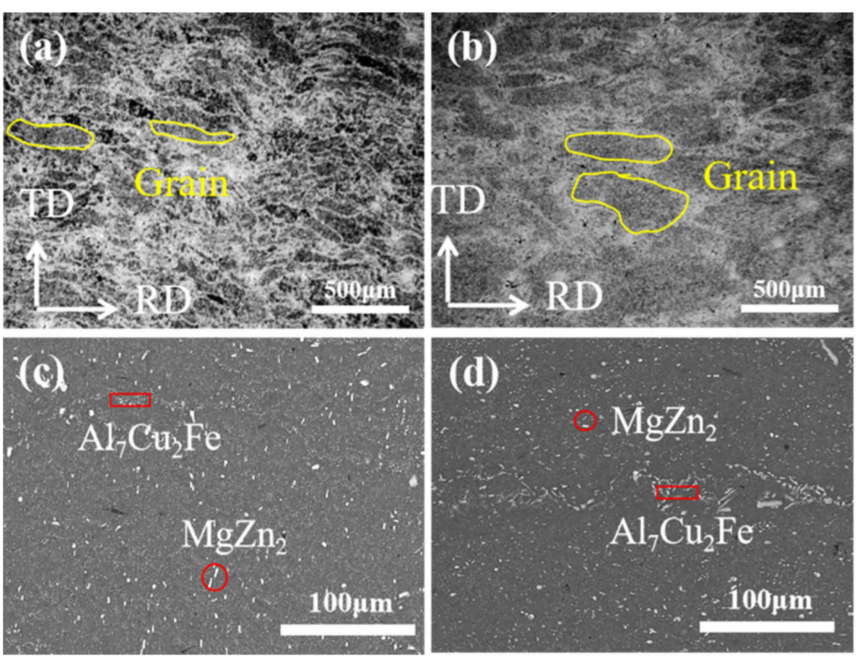

Figure 1. Grain structure and SEM results of hot rolled plates: (a,c) $25 \mathrm{~mm}$; (b,d) $65 \mathrm{~mm}$.

Figure 2 presents the IPF and BC images of the $25 \mathrm{~mm}$ and $65 \mathrm{~mm}$ plates. As can be observed from Figure 2a,c, the grain orientation of the $25 \mathrm{~mm}$ plate can be divided into two categories. Grains with lower degrees of LAGBs tend to the orientation of [101] along the ND, and grains that have higher degrees of LAGBs tend to the orientation between [001] and [111]. It is obvious that the density of the LAGBs in the $65 \mathrm{~mm}$ plate (with the fraction 0.167) is significantly lower than that in the $25 \mathrm{~mm}$ (with the fraction 0.317) plate. The results indicate that with the increase of degrees of deformation, the density of the LAGBs increases rapidly. Meanwhile, the LAGBs always exist in the broken small grains and around grain boundaries. A similar discovery was discussed in previous experiments with the $120 \mathrm{~mm}$ plate.
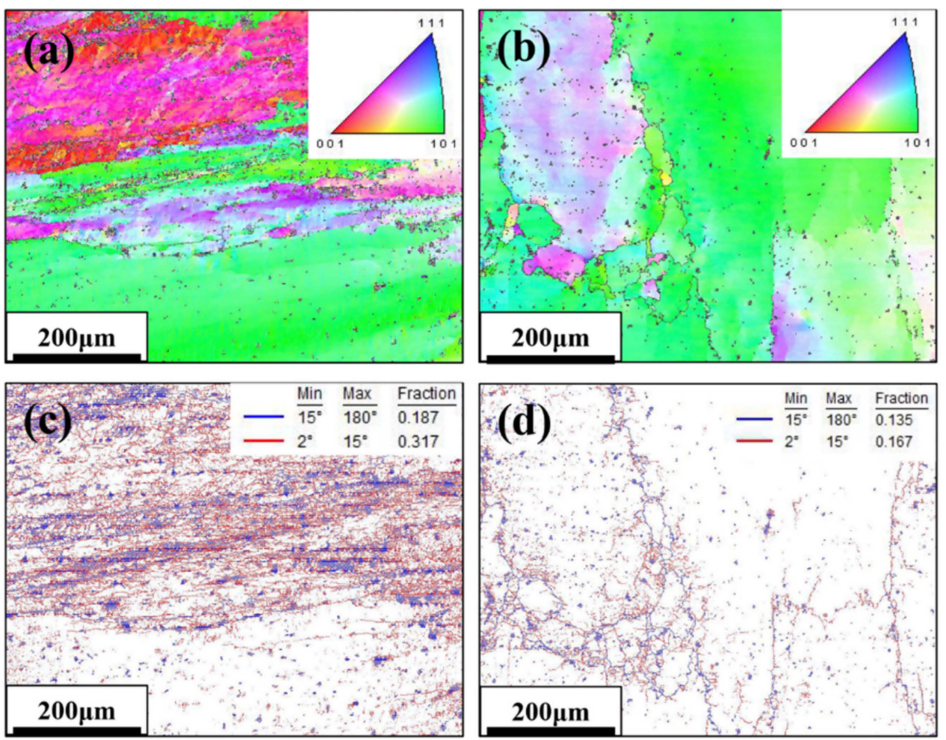

Figure 2. IPF results and boundary contrast $(B C)$ images of hot rolled plates: $(\mathbf{a}, \mathbf{c}) 25 \mathrm{~mm}$; (b,d) $65 \mathrm{~mm}$. 
To characterize texture types and orientation densities of the plates in different thicknesses, ODF maps are shown in Figure 3. In the $25 \mathrm{~mm}$ plate, the main textures are Brass $\{011\}<211>, R\{124\}<211>$, Cube $\{001\}<100>$, Copper $\{112\}<111>$ and Goss $\{011\}<100>$. The Goss texture almost disappears in the $65 \mathrm{~mm}$ plate (Figure $3 \mathrm{~b}$ ) and disappears completely in the $120 \mathrm{~mm}$ plate (Figure 3c). Texture types change significantly when the thickness of the plate increases to $120 \mathrm{~mm}$. The main textures in the $120 \mathrm{~mm}$ plate change from Brass, $\mathrm{R}$ to Cube, R-Cube. Meanwhile, the value of orientation density decreases dramatically. The texture types and orientation density of the plates are shown in Table 1.

(a)
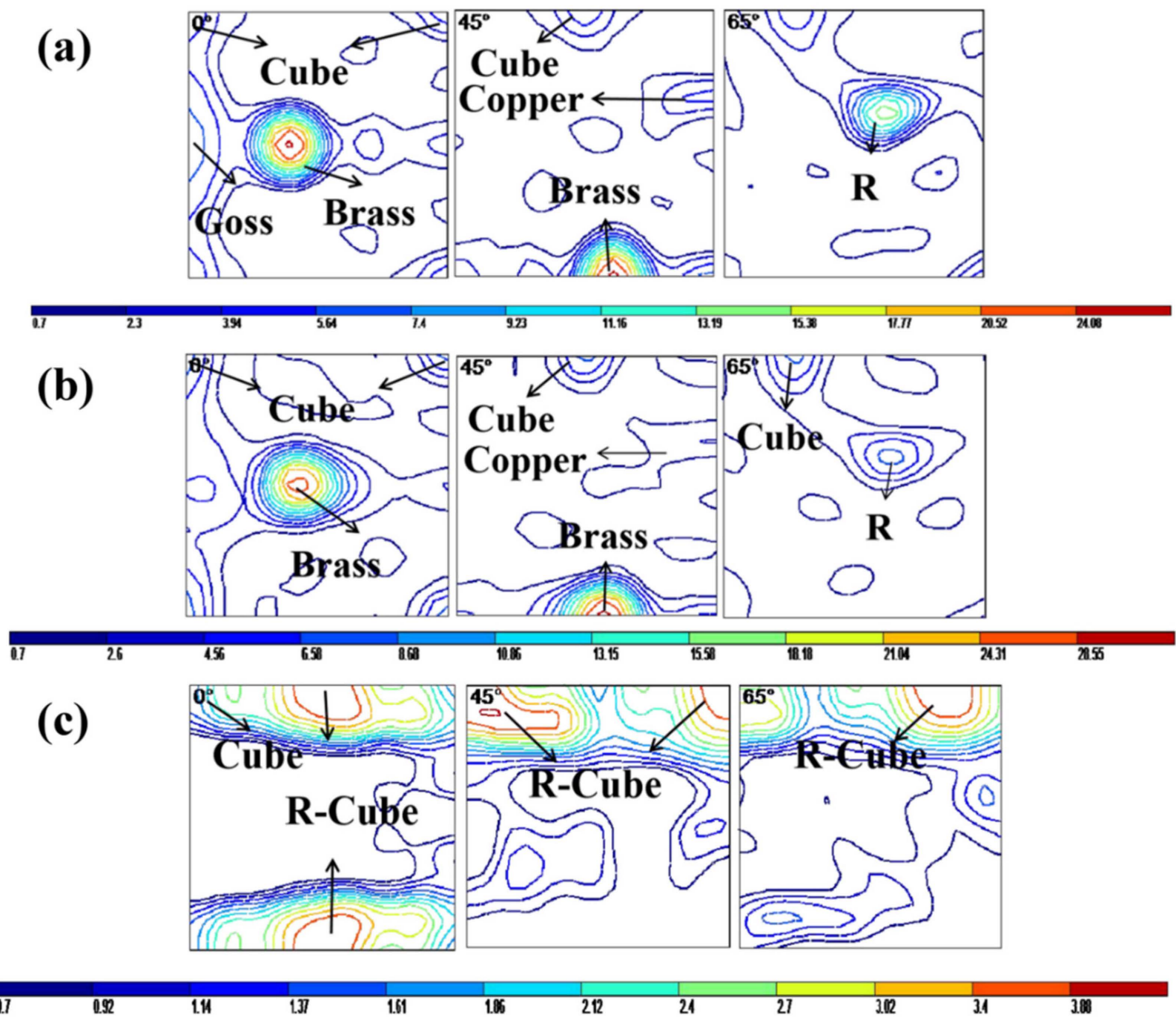

Figure 3. ODF maps of hot rolled plates: (a) $25 \mathrm{~mm}$, (b) $65 \mathrm{~mm}$, (c) $120 \mathrm{~mm}$.

Table 1. The texture types and orientation density of the plates.

\begin{tabular}{ccccccc}
\hline Plate Thickness & Cube & Brass & Copper & $\mathbf{R}$ & R-Cube & Goss \\
\hline $25 \mathrm{~mm}$ & $3.94-5.94$ & $24.00-$ & $3.94-5.64$ & $13.19-15.38$ & - & $5.64-7.4$ \\
$65 \mathrm{~mm}$ & $6.58-8.68$ & $28.6-$ & $2.6-4.56$ & $6.58-8.68$ & - & - \\
$120 \mathrm{~mm}$ & $1.37-1.61$ & - & - & - & $3.88-$ & - \\
\hline
\end{tabular}

\subsection{Microstructure of Hot Rolled Plates after Different Solution Time}

Figure 4 presents SEM images of different plates after different solution times. It can be observed that the $\mathrm{MgZn}_{2}$ phase redissolves into the $\mathrm{Al}$ matrix partially after 30 min solution treatment, and the plate almost completes the re-dissolution process after 90 min solution 
treatment, as shown in Figure $4 \mathrm{a}, \mathrm{b}$ (microstructure in the $25 \mathrm{~mm}$ plate) and Figure $4 \mathrm{e}, \mathrm{f}$ (microstructure in the $120 \mathrm{~mm}$ plate). The $\mathrm{MgZn}_{2}$ phase almost redissolves into the matrix after 30 min solution treatment (as shown in Figure 4c,d) indicating that the re-dissolution process in the $65 \mathrm{~mm}$ plate is faster than in the other two plates. Compared with the re-dissolution speed of the $25 \mathrm{~mm}$ and $120 \mathrm{~mm}$ plates, the $\mathrm{MgZn}$ 2 phase is difficult to dissolve in the $120 \mathrm{~mm}$ plate at the beginning of the solution.
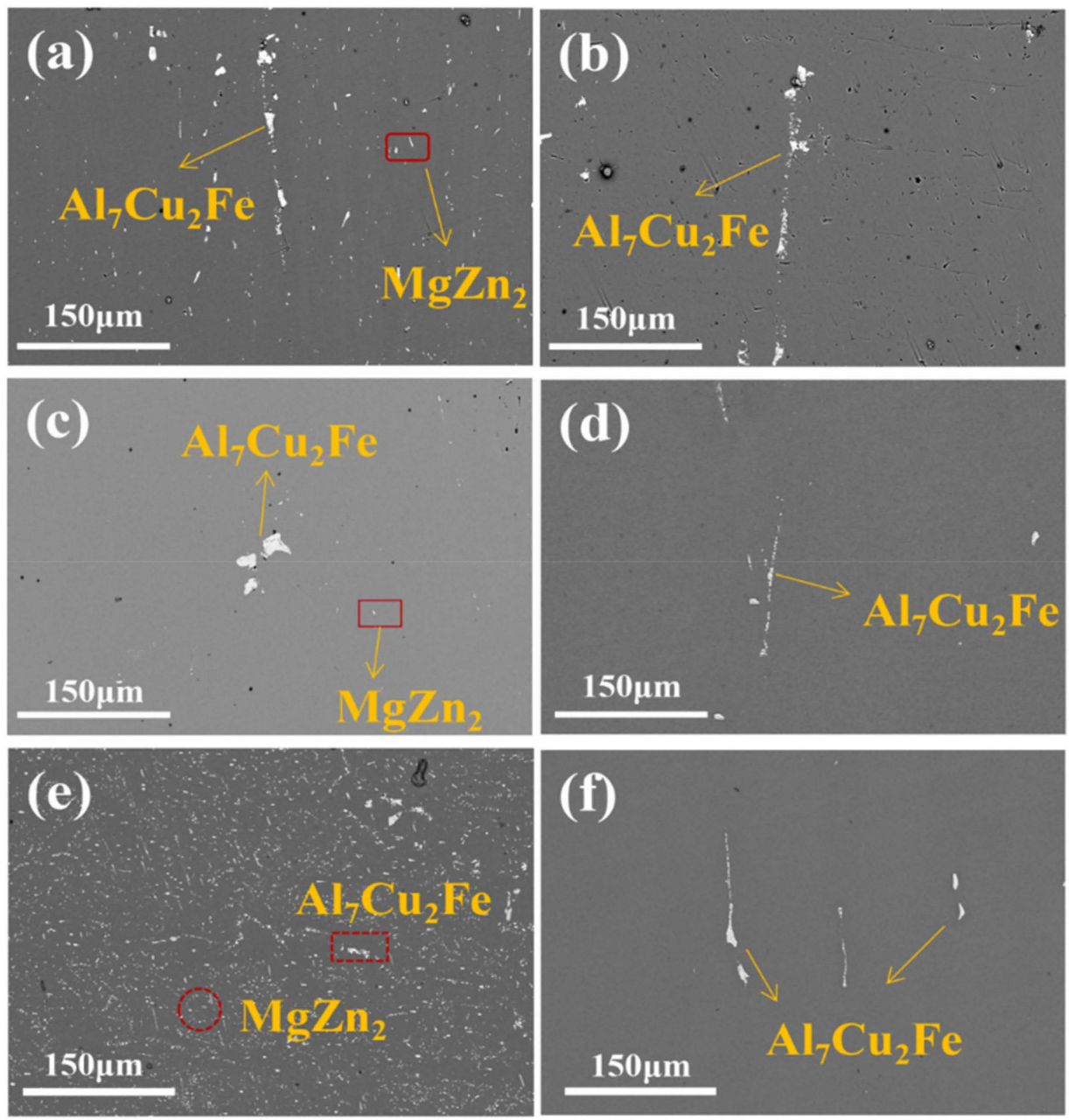

Figure 4. SEM figures of $25 / 65 / 120 \mathrm{~mm}$ hot rolled plates after solution at: $(\mathbf{a}, \mathbf{c}, \mathbf{e}) 477^{\circ} \mathrm{C} / 30 \mathrm{~min}$; $(\mathbf{b}, \mathbf{d}, \mathbf{f}) 477^{\circ} \mathrm{C} / 90 \mathrm{~min}$.

Figure 5 shows IPF and BC images of the different plates after different solution times. As shown in Figure 5a,d, grain orientation changes acutely and is more complex compared with the microstructure in the hot rolled state for the $25 \mathrm{~mm}$ plate (Figure 2a). Most of the grains are in the process of recrystallization and a fraction of new recrystallized grains can be observed. The new recrystallized grains remain in the deformed structure. For the $65 \mathrm{~mm}$ plate (Figure 5b,e), the degree of recrystallization is lower than that of the $25 \mathrm{~mm}$ plate after the solution treatment. Simultaneously, grains that have already been recrystallized remain in the deformed structure. A similar phenomenon can be observed in the $120 \mathrm{~mm}$ plate (Figure 5c,f). The grain morphology of the $65 \mathrm{~mm}$ and $120 \mathrm{~mm}$ plates remains unchanged after the $\mathrm{MgZn}_{2}$ phase is basically dissolved; however, that of the $25 \mathrm{~mm}$ plate changes to a distinctly banded shape. 

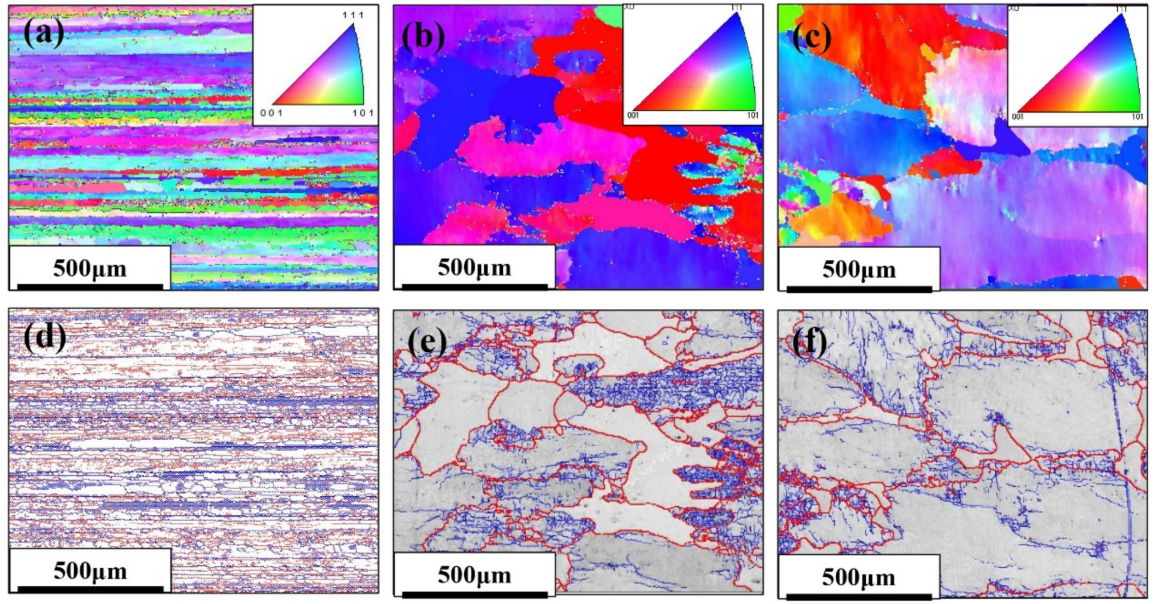

Figure 5. IPF and BC images of the different plates after different solution times: (a,d) the $25 \mathrm{~mm}$ plate treated for $90 \mathrm{~min}$; $(\mathbf{b}, \mathbf{e})$ the $65 \mathrm{~mm}$ plate treated for $30 \mathrm{~min}$; $(\mathbf{c}, \mathbf{f})$ the $120 \mathrm{~mm}$ plate treated for $90 \mathrm{~min}$.

Figure 6 shows the ODF maps of the $25 \mathrm{~mm}$ plate after solution at $477^{\circ} \mathrm{C}$ for different times. Compared with the texture before solution treatment (as shown in Figure 3a), texture types do not change significantly and the main discrepancy is orientation density. The main textures are as follows: high orientation density of Brass, $\mathrm{R}$ and low orientation density of Copper, Cube, Goss. In the re-dissolution process (0-90 $\mathrm{min}$ ), the volume fraction of Brass texture decreases (the volume fraction changes from $44.0 \%$ to $41.1 \%$ ). After the re-dissolution process, the volume fraction of Brass texture first increases (the volume fraction changes from $41.1 \%$ to $43.6 \%$ ) and then decreases (the volume fraction changes from $43.6 \%$ to $39.7 \%)$.

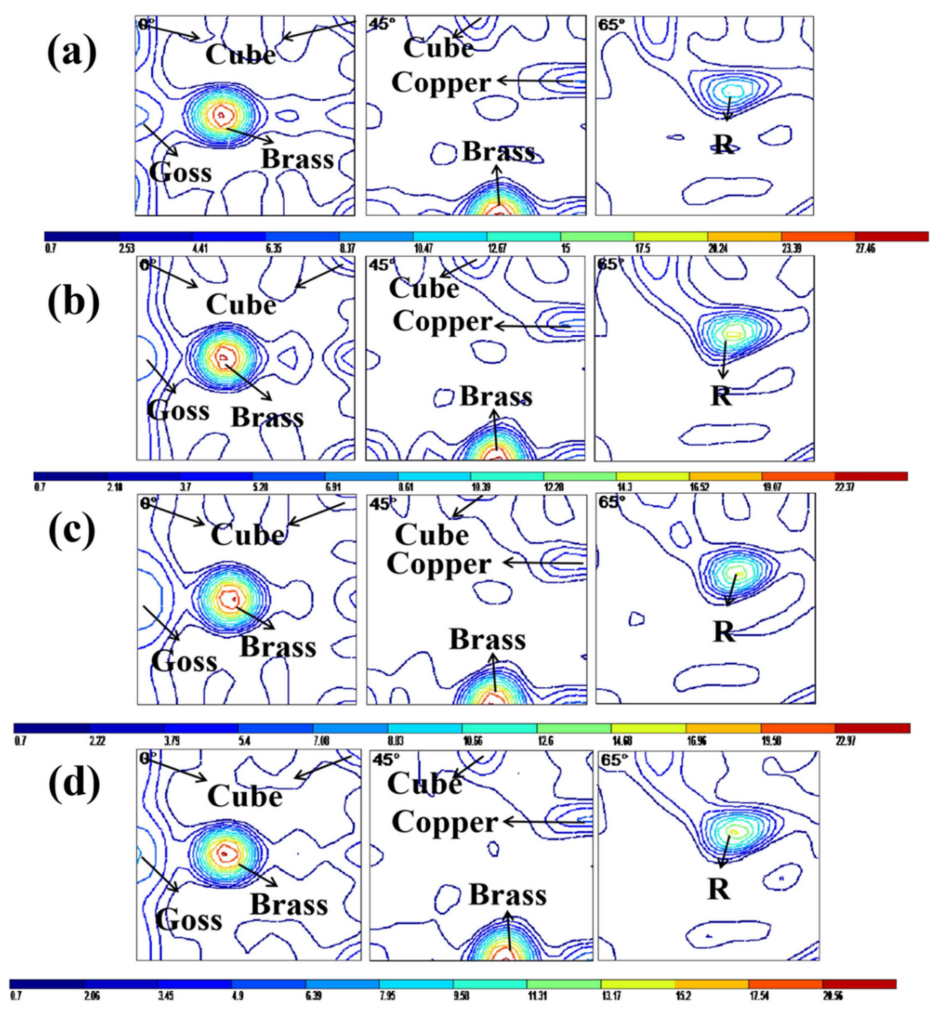

Figure 6. ODF results of the $25 \mathrm{~mm}$ hot rolled plate after solution at $477^{\circ} \mathrm{C}$ for: (a) $30 \mathrm{~min}$, (b) $90 \mathrm{~min}$, (c) $210 \mathrm{~min}$, (d) $330 \mathrm{~min}$. 
As can be observed from Figure 7, texture types for the $65 \mathrm{~mm}$ plate do not change after solution treatment at different times which is the same as the $25 \mathrm{~mm}$ plate. The main texture is a high orientation density of Brass and a low orientation density of R, Cube, Copper. Goss texture does not occur during solution treatment, indicating that it is mainly controlled by the deformation process. The volume fraction of Brass texture decreases in the re-dissolution process (0-30 $\mathrm{min}$ ), and the volume fraction changes from $60.3 \%$ to $54.3 \%$. The same phenomenon that the volume fraction of Brass texture first increases (the volume fraction changes from $54.3 \%$ to $66.0 \%$ ) and then decreases (the volume fraction changes from $66.0 \%$ to $62.4 \%$ ) can be observed in the $65 \mathrm{~mm}$ plate as well.

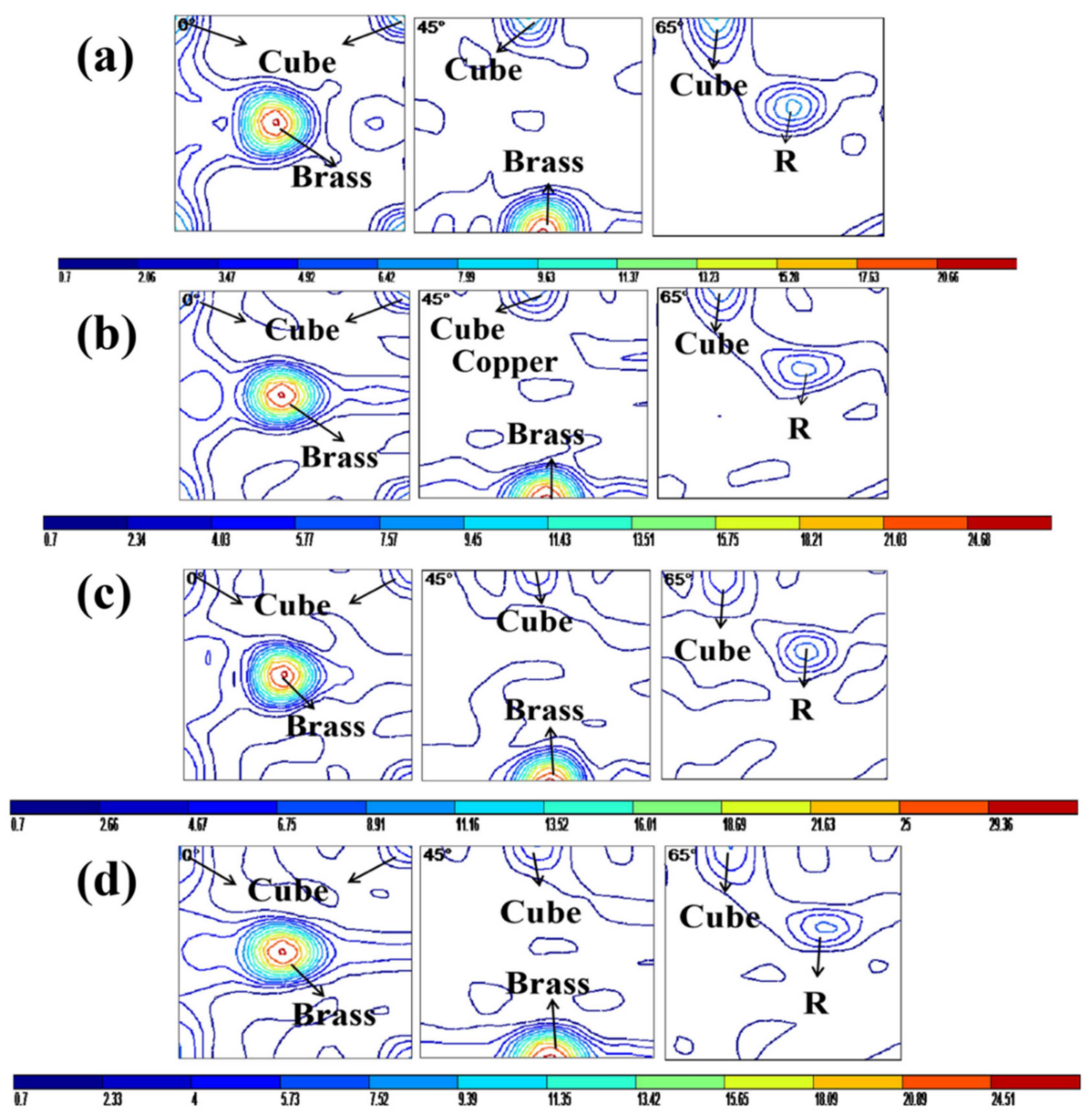

Figure 7. ODF results of $65 \mathrm{~mm}$ hot rolled plates after solution at $477^{\circ} \mathrm{C}$ for: (a) $30 \mathrm{~min}$, (b) $90 \mathrm{~min}$, (c) $210 \mathrm{~min}$, (d) $330 \mathrm{~min}$.

The ODF results of the $120 \mathrm{~mm}$ plate are shown in Figure 8 to confirm the texture evolution after the solution treatment. The texture types change dramatically at the beginning of the solution treatment (as shown in Figures $3 \mathrm{c}$ and $8 \mathrm{a}$ ), which is contrary to other plates. R-Cube texture disappears and Brass, Copper, $\mathrm{R}$ texture appear after the solution treatment for $30 \mathrm{~min}$. The texture types do not change but the orientation density has different changes with the extension of solution time. The volume fraction of Brass texture goes through a similar process of the $25 \mathrm{~mm}$ plate in the re-dissolution process (the volume fraction increases from 0 to $47.9 \%$ and then decreases to $41.5 \%$ ). After the re-dissolution process, the volume fraction of Brass texture also goes through the comparable process like the trend in the re-dissolution process (the volume fraction transforms from $41.5 \%$ to $49.9 \%$ and then decreases to $49.6 \%$ ). The evolution trends of other textures are discussed in Figure 9. 


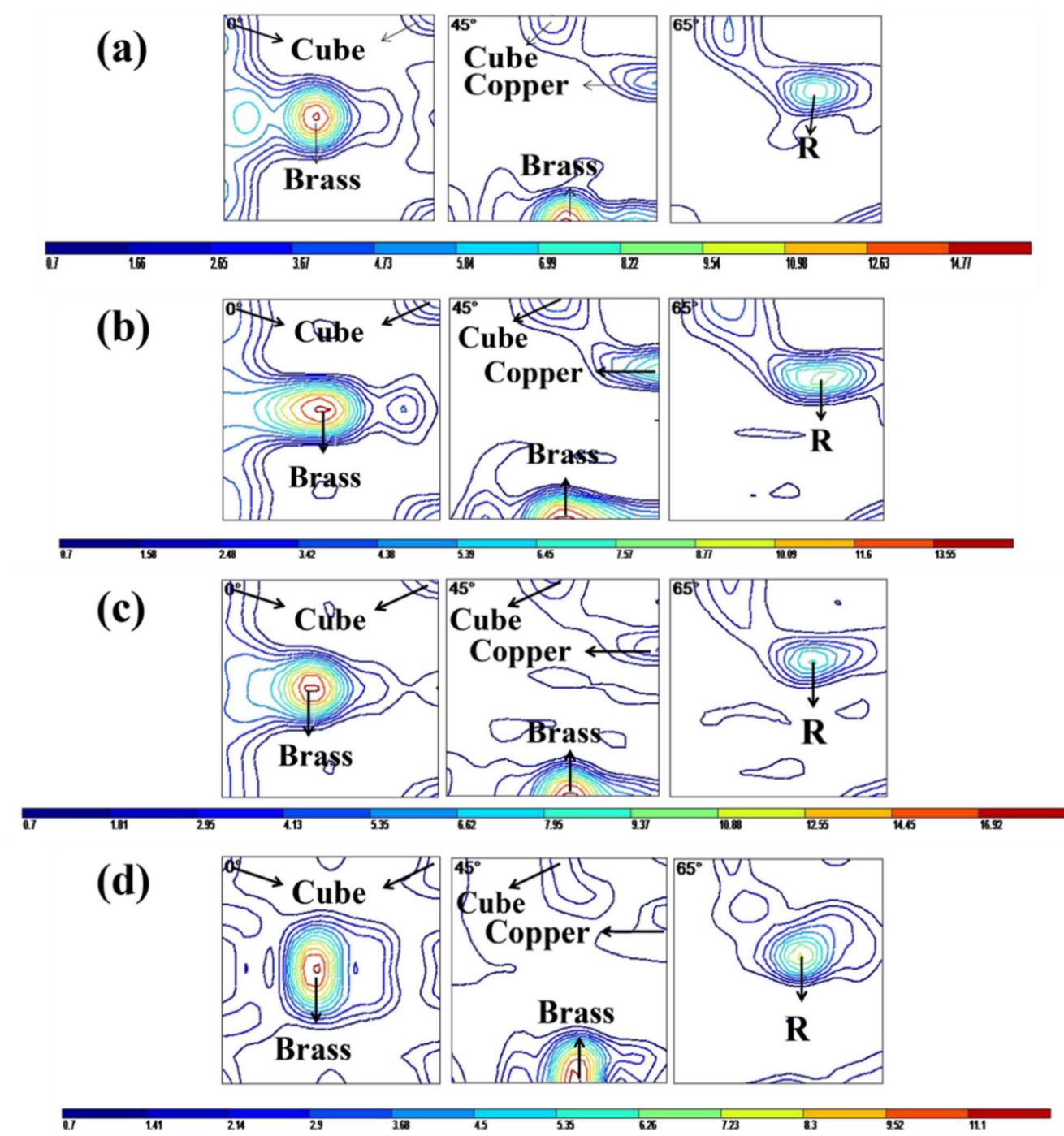

Figure 8. ODF results of the $120 \mathrm{~mm}$ hot rolled plate after solution at $477^{\circ} \mathrm{C}$ for: (a) $30 \mathrm{~min}$, (b) $90 \mathrm{~min}$, (c) $210 \mathrm{~min}$, (d) $330 \mathrm{~min}$.

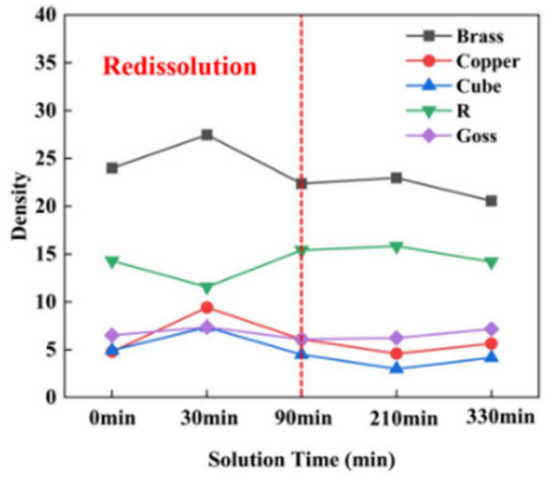

(a)

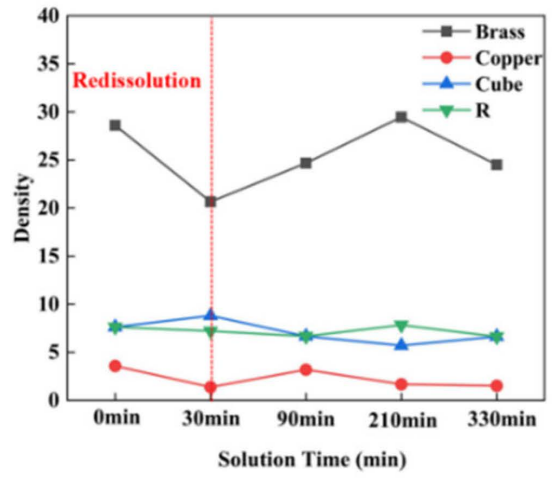

(b)

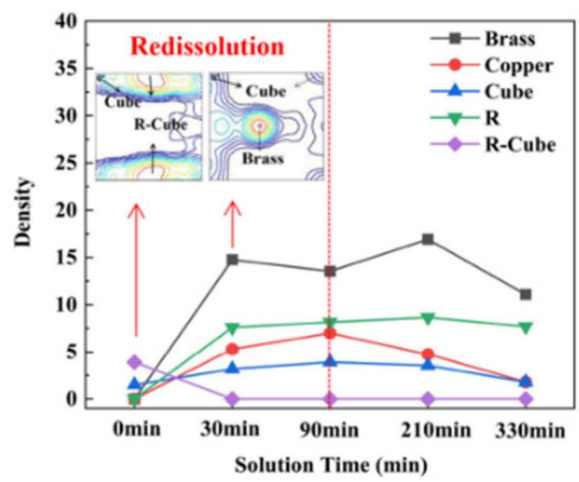

(c)

Figure 9. Curves of the texture orientation density after different solution times: (a) $25 \mathrm{~mm}$, (b) $65 \mathrm{~mm}$, (c) $120 \mathrm{~mm}$.

Figure 9 shows the curves of the orientation density after different solution times. The mean of the orientation density range is adopted as the nominal orientation density to 
draw the curves of the orientation density after treatment for different solution times. The orientation density of texture shows different trends for the three plates owing to their distinction in the initial texture and re-dissolution process. The solution process can be divided into the re-dissolution process and the process after re-dissolution.

For the $25 \mathrm{~mm}$ plate, as shown in Figure 9a, the orientation density of Goss texture basically remains the same in the whole process. In the re-dissolution process, the variation trend in the orientation density of Copper and Cube texture is similar to that for Brass texture. However, the orientation density of $\mathrm{R}$ texture exhibits the opposite trend compared with other textures. The orientation densities of Brass and $\mathrm{R}$ textures experience a slight increase and then decrease after re-dissolution, which is opposite to the trend of Cube and Copper.

As presented in Figure 9b, for the $65 \mathrm{~mm}$ plate, the orientation density of Copper remains low in the process of solution treatment. The orientation density of Cube and $\mathrm{R}$ fluctuates within a certain range and the value ranges from 6 to 10. The Brass texture is still the main texture in the $65 \mathrm{~mm}$ plate which is greatly affected by the solution time. In particular, the orientation density of Brass peaks after $210 \mathrm{~min}$ solution treatment (the orientation density is 29.36) and then decreases.

The orientation density of the $120 \mathrm{~mm}$ plate is shown in Figure 9c. The evolution of texture is different from other plates in the solution process. At the preliminary stage of solution, textures change extraordinarily in the first $30 \mathrm{~min}$ and then remain basically unchanged in the following $60 \mathrm{~min}$. The evolution trend of Brass texture is similar to that of the $65 \mathrm{~mm}$ plate after the re-dissolution process. The orientation densities of Copper and Cube texture decrease while the orientation density of $\mathrm{R}$ texture remains unchanged, with the deepening of the solid solution process.

The IPF results of different hot rolled plates after different solution treatments are shown in Figure 10. The orientation of the $25 \mathrm{~mm}$ plate along the RD is mainly $\langle 112\rangle$ (the orientation density is 6.54) and $<001>$ (the orientation density ranges from 4.37 to 4.97 ), and the orientation along the TD is $<111>$ (the orientation density ranges from 4.97 to 5.65 ). The orientation of the $65 \mathrm{~mm}$ plate is analogous to that of the $25 \mathrm{~mm}$ plate, as shown in Figure 10a,b. It is apparent from Figure 10c that the orientation of the $120 \mathrm{~mm}$ plate along the rolling direction is chiefly $<111>$ (the value ranges from 4.81-5.47) and $<001\rangle$ (the value ranges from 4.23-4.81). However, the orientation along the TD is not obvious.

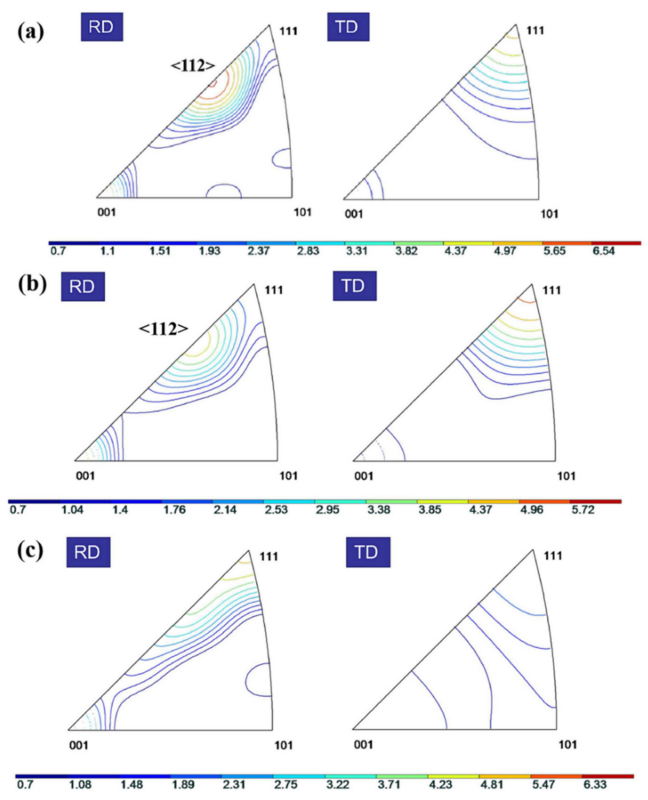

Figure 10. IPF results of hot rolled plates after different solution treatments: (a) $25 \mathrm{~mm}$ plates treated for $90 \mathrm{~min}$; (b) $65 \mathrm{~mm}$ plates treated for $30 \mathrm{~min}$; (c) $120 \mathrm{~mm}$ plates treated for $90 \mathrm{~min}$. 


\subsection{Properties of Hot Rolled Plates after Different Solution Times}

To further analyze the re-dissolution process, conductivity was measured after different solution times, as presented in Figure 11. In the first $30 \mathrm{~min}$, the conductivity value decreases rapidly, indicating that re-dissolution has occurred. In the following $60 \mathrm{~min}$, the conductivity further decreases for the $25 \mathrm{~mm}$ and $120 \mathrm{~mm}$ plates; however, for the $65 \mathrm{~mm}$ plate, it remains approximately unchanged. With longer solution treatments, the conductivity does not change significantly.

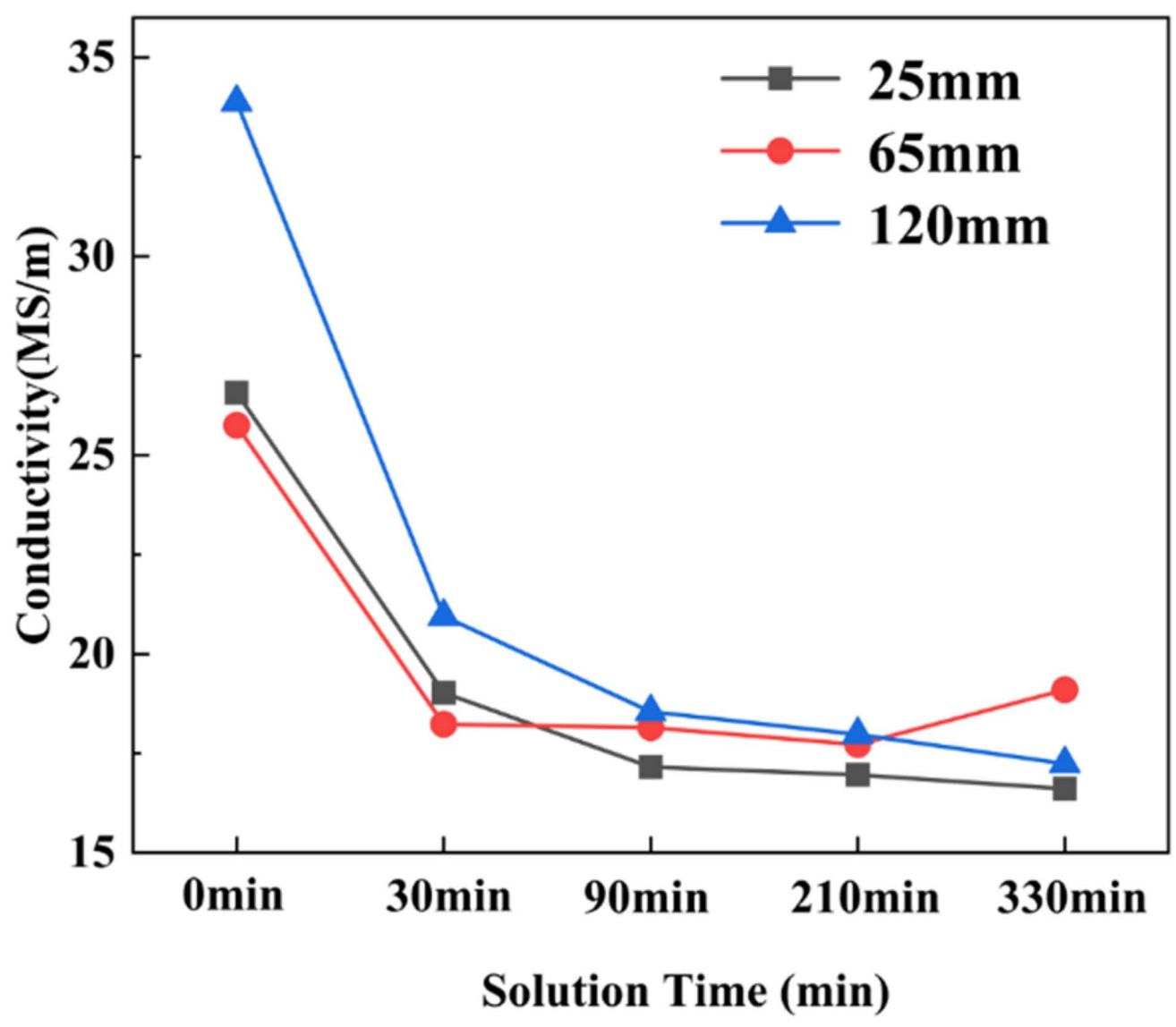

Figure 11. Conductivity results after different solution times.

Figure 12 shows the mechanical properties of the plates after solution and ageing treatment. For the $25 \mathrm{~mm}$ plate, the mechanical performance after $90 \mathrm{~min}$ solution treatment is distinctly better than that after $30 \mathrm{~min}$ treatment. The tensile strength is increased by about $90 \mathrm{MPa}$ and the elongation after fracture is improved especially along the TD. The same tendency can be observed in the $120 \mathrm{~mm}$ plate: the tensile strength is increased by about $130 \mathrm{MPa}$ which is more obvious than that for the $25 \mathrm{~mm}$ plate. As shown in Figure $9 \mathrm{~b}$, the orientation density of Brass rises to the maximum after 210 min solution treatment. Thus, the mechanical properties after $210 \mathrm{~min}$ treatment were tested for the $65 \mathrm{~mm}$ plate. The elongation after fracture of the $65 \mathrm{~mm}$ plate decreased rapidly under the $477^{\circ} \mathrm{C} / 210$ min solution treatment compared with the treatment of $477^{\circ} \mathrm{C} / 30 \mathrm{~min}$ (the value changes from $\sim 10.5$ to $\sim 1.5$ ). Meanwhile, the tensile strength decreases by about $35 \mathrm{MPa}$. 

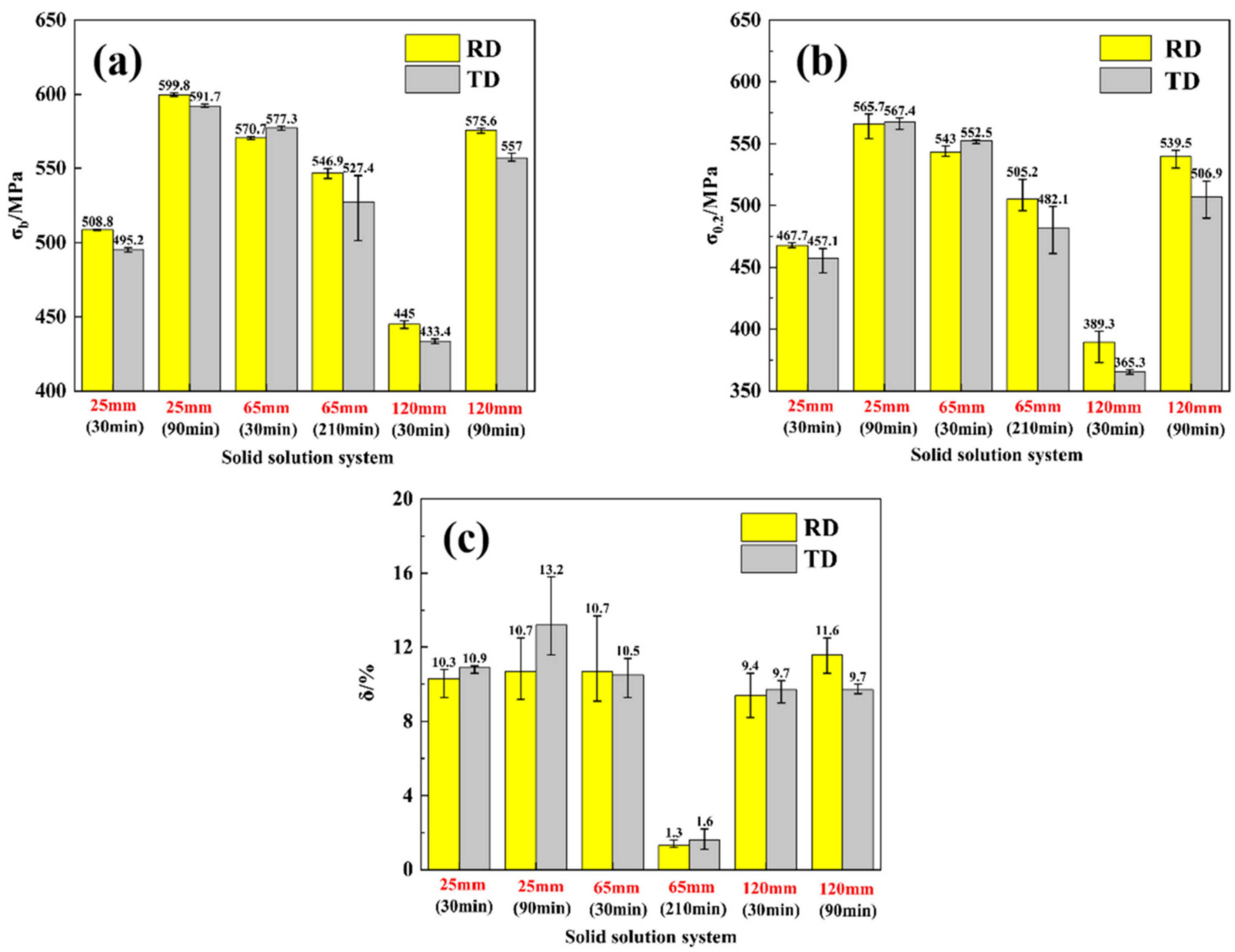

Figure 12. Mechanical properties of the plates after solution and ageing treatments: $(\mathbf{a}) \sigma_{\mathrm{b},}(\mathbf{b}) \sigma_{0.2},(\mathbf{c}) \delta$.

\section{Discussion}

\subsection{Analysis of the Potential Slip Systems in Theory during Tension}

According to the results of IPF, as shown in Figure 10, the slip systems of different plates can be calculated under the method of Schmidt's law [29]. Schmidt's law can be estimated by:

$$
\tau=\sigma \cos \alpha \cos \beta=\sigma \mu,
$$

where $\tau$ is the sheer stress, $\sigma$ is the normal stress, $\alpha$ is the angle between the direction of $\sigma$ and slip, $\beta$ is the angle between the direction of $\sigma$ and the normal direction of the slip surface and $\mu$ is the Schmid factor. For FCC metals, there are four equivalent slip planes and three equivalent slip directions. The value of $\mu$ changes greatly along different directions in different plates. The orientation and density along RD and TD of different plates are shown in Table 2. The activated slip systems are dependent on the stretching orientations. When the direction of extrusion is $\langle 112\rangle$, the confirmed slip system should be the one with the largest $\mu$ value. The slip systems and the value of $\mu$ are shown in Table 3 . On account of the [111] orientation being perpendicular to the slip directions, the slip systems start with difficulty and the value of $\mu$ is 0 . At the beginning of the stretch process, the slip systems of grains with the orientation of [112] and [001] start first and other slip systems start in the subsequent plastic deformation process. The orientation and densities are different in different plates along $\mathrm{RD}$ and $\mathrm{TD}$, and the average value of $\mu(\bar{\mu})$ can be calculated to reflect the mechanical behavior of the plates. In the process of calculation, only the main orientations are considered. The values of $\bar{\mu}$ in the plates with different thicknesses are shown in Table 4 . In general, the value of $\mu$ is inversely proportional to the 
yield strength [30]. Thus, the yield strength along the RD is smaller than that along the TD for the $25 \mathrm{~mm}$ and $65 \mathrm{~mm}$ plates. For the $120 \mathrm{~mm}$ plate, the yield strength along the RD and TD has a great difference on account of the inconspicuous fiber texture along the TD (Figure 10c). Owing to the value of $\mu$ being related to the value of $\mathrm{M}$ (the Taylor factor), the analysis of the value of the $\mu$ is the basis to analyze the theoretical yield strength in the following discussion in Section 4.3.

Table 2. The orientations and orientation densities of different plates.

\begin{tabular}{ccccc}
\hline Plate Thickness & \multicolumn{2}{c}{ RD } & \multicolumn{2}{c}{ TD } \\
\hline \multirow{2}{*}{$25 \mathrm{~mm}$} & {$[112]$} & 6.54 & {$[111]$} & $4.97-5.65$ \\
& {$[001]$} & $4.37-4.97$ & {$[001]$} & $1.11-1.51$ \\
$65 \mathrm{~mm}$ & {$[112]$} & $3.85-4.37$ & {$[111]$} & $4.96-5.72$ \\
& {$[001]$} & $3.85-4.37$ & {$[001]$} & $1.4-1.76$ \\
\multirow{2}{*}{$120 \mathrm{~mm}$} & {$[111]$} & $4.81-5.47$ & & \multicolumn{2}{c}{} \\
& {$[001]$} & $4.23-4.81$ & & \\
\hline
\end{tabular}

Table 3. The orientations, slip systems and the value of $\mu$.

\begin{tabular}{ccc}
\hline Orientation & Slip Systems & $\mu$ \\
\hline$[112]$ & $(111)<\overline{1} 01>,(111)<01 \overline{1}>$ & 0.27 \\
{$[001]$} & $(111)<\overline{1} 01>,(\overline{1} 11)<\overline{1} 01>,(1 \overline{1} 1)<\overline{1} 01>,(11 \overline{1})<\overline{1} 01>$ & 0.41 \\
{$[111]$} & $(111)<01 \overline{1}>,(\overline{1} 11)<01 \overline{1}>,(1 \overline{1} 1)<01 \overline{1}>,(11 \overline{1})<01 \overline{1}>$ & 0 \\
\hline
\end{tabular}

Table 4. The value of $\bar{\mu}$ in the plates with different thicknesses.

\begin{tabular}{ccc}
\hline Plate Thickness & $\bar{\mu} / \mathbf{R D}$ & $\bar{\mu} / \mathrm{TD}$ \\
\hline $25 \mathrm{~mm}$ & 0.33 & 0.08 \\
$65 \mathrm{~mm}$ & 0.34 & 0.09 \\
$120 \mathrm{~mm}$ & 0.19 & - \\
\hline
\end{tabular}

\subsection{Influence of Different Solution Times on the Texture Evolution and Mechanical Properties}

For the hot rolled plates, textures play a significant role in their mechanical anisotropy, and the different evolution of textures during solution treatment affects the mechanical properties dissimilarly $[26,27]$. According to the results above, the changes of textures in the plates are affected by two main factors: one is the initial textures of the plates, the other is the re-dissolution of the second phase.

For the $25 \mathrm{~mm}$ and $65 \mathrm{~mm}$ plate, the main texture is Brass $\{011\}<211>$ and $R\{124\}<211>$ with high orientation density due to the influence of deformation. However, the texture in the $120 \mathrm{~mm}$ plate is not obvious since the degree of deformation is not high, and the main texture is R-Cube $\{001\}<110>$ and Cube $\{001\}<100>$ (Figure 3). Different trends are shown at the beginning of the solution process for the different initial textures. It can be observed that no matter what the initial textures are, textures change to the combination of Brass, R, Cube and Copper $\{112\}<111>$ after solution treatments (Figures 5-7). According to the analysis above, with the increase of deformation degrees, textures change to Brass, $\mathrm{R}$, Cube and Copper which is the same trend caused by static recrystallization. In the solution process, the force from static recrystallization makes the texture evolution occur and develop rapidly in $30 \mathrm{~min}$. To sum up, with the increase of deformation and static recrystallization, texture types change from Cube, R-Cube to Brass, R, Cube and Copper during the re-dissolution process. Meanwhile, the evolution of texture occurs simultaneously in the process of redissolution. However, it is difficult to identify the relationship between re-dissolution and texture evolution.

After the re-dissolution process is completed, similar trends can be observed in the three plates, namely, that the orientation density of Brass texture first increases and then 
decreases. As shown in Figure 12, the elongation after fracture of the $65 \mathrm{~mm}$ plate decreases rapidly because the orientation density of Brass texture increases greatly, which is seldom reported by other researchers. According to the analysis in Section 4.1, in the process of tensile experiments, the Schmid factor $(\mu)$ is related to the mechanical properties [29]. According to previous research, the Schmid factor of the Brass texture along the TD is larger than that along the RD. Generally speaking, the yield strength is inversely proportional to the Schmid factor [30]. Therefore, the value of yield strength is smaller along the TD. The slip systems are difficult to operate as the orientation density of Brass texture rises to a specific level, so that the elongation after fracture decreases sharply. As a result, there is almost no theoretical foundation about the reason why the high orientation density of Brass leads to the sharp decrease in the elongation in the previous studies. Thus, in order to improve the mechanical properties of the plates, the solution time should be selected as the moment when the microstructure has just completed the re-dissolution process. When the solution time is too long, the elongation decreases greatly on account of the orientation density of Brass increases.

\subsection{Influence of Re-Dissolution and Recrystallization}

In general, the second phases in the hot rolled plate are mainly $\mathrm{MgZn}_{2}$ and $\mathrm{Al}_{7} \mathrm{Cu}_{2} \mathrm{Fe}$, as shown in Figure 1. As the deformation increases, the $\mathrm{Al}_{7} \mathrm{Cu}_{2} \mathrm{Fe}$ phase is separated and does not distribute along grain boundaries. The re-dissolution of the second phase exhibits different trends as the deformation increases as well. For the $25 \mathrm{~mm}$ and $120 \mathrm{~mm}$ plates, the rate of re-dissolution is slower than that of the $65 \mathrm{~mm}$ plate, as can be observed in Figure 4 . The same conclusion can be obtained from the conductivity results, which confirm the accuracy of the re-dissolution process. The degree of lattice distortion of the Al matrix is the main factor that affects the conductivity in the re-dissolution process [31]. At the beginning of the re-dissolution process (0-30 $\mathrm{min}$ ), a large amount of $\mathrm{MgZn_{2 }}$ phases dissolve into the matrix, which causes an increase in the degree of lattice distortion. The increase in lattice distortion leads to the scattering of the electrons during conduction which causes the conductivity to decrease rapidly. In the following $60 \mathrm{~min}$ (30-90 $\mathrm{min}$ ), the conductivity decreases in the $25 \mathrm{~mm}$ and $120 \mathrm{~mm}$ plate and remains unchanged in the $65 \mathrm{~mm}$ plate, indicating that the $\mathrm{MgZn} 2$ phase further dissolves in the $25 \mathrm{~mm}$ and $120 \mathrm{~mm}$ plate. The existence of the $\mathrm{MgZn}$ 2 phase affects the mechanical properties, as presented in Figure 12. The analyses above indicate that to obtain better mechanical properties, the first step is to make sure that the re-dissolution process is mainly completed.

After the re-dissolution process is completed, different plates exhibit different degrees of recrystallization. The theoretical yield strength can be described as [32]:

$$
\sigma_{0.2}=\sigma_{0}+\sigma_{\mathrm{ss}}+\sigma_{g s}+\sigma_{d},
$$

where $\sigma_{0}$ represents the yield strength of pure Al matrix, $\sigma_{\mathrm{ss}}$ is the strength affected by the solid solution, $\sigma_{\mathrm{gs}}$ is the strengthening effect of grain boundaries and $\sigma_{\mathrm{d}}$ is the strength affected by the dislocation density. In addition to the above four factors, the strength affected by age hardening is also an important factor for all solution-treated and aged $\mathrm{Al}-\mathrm{Zn}-\mathrm{Mg}-\mathrm{Cu}$ alloys. However, since the aging treatment is unchanged in this study, the effect caused by age hardening in this study is considered to be similar.

For the plates analyzed in the experiment, $\sigma_{0}$ is a constant value. $\sigma_{\mathrm{ss}}$ can be expressed as [32]:

$$
\sigma_{\mathrm{ss}}=\mathrm{M}\left(\tau_{1}^{\frac{3}{2}}+\tau_{2}^{\frac{3}{2}}+\tau_{3}^{\frac{3}{2}}+\ldots\right)^{\frac{2}{3}}
$$

where $M$ represents the Taylor factor and $\tau$ represents the strength contribution caused by the solute atoms. The value of $\tau$ is affected by many factors, such as temperature, the concentration of the solute elements, the strain rate and the energy barrier to overcome dislocation motion. In general, the energy to overcome dislocation motion decreases as deformation increases. Meanwhile, the value of $\sigma_{\mathrm{ss}}$ is positively correlated with the value of the energy barrier. Thus, the $\tau$ value of the $25 \mathrm{~mm}$ plate is slightly smaller than that of the $65 \mathrm{~mm}$ and $120 \mathrm{~mm}$ plates. According to the plates tested, other factors above are 
approximate due to the second phase being mainly dissolved into the matrix; therefore, the main factors that affect the $\sigma_{\mathrm{ss}}$ are the value of $\mathrm{M}$ and the energy barrier. The value of $\sigma_{\mathrm{gs}}$ can be estimated by the Hall-Petch formula $\left(\sigma_{\mathrm{gs}}=\sigma_{0}+\mathrm{kd}^{-1 / 2}\right)$. It is obvious that with the increase of thickness, grain sizes increase. The value of $\sigma_{d}$ can be expressed as [33]:

$$
\sigma_{\mathrm{d}}=\alpha G M B \rho^{\frac{1}{2}}
$$

where $\alpha$ is a constant value, $G$ is the shear modulus of aluminum, $B$ is the Burgers vector, $\rho$ is the dislocation density and $M$ is the Taylor factor. On account of the plates having different degrees of deformation and recrystallization, the value of $M, \rho$ is different. Grain boundaries can absorb dislocation and then the dislocation density decreases. Thus, the dislocation density decreases with the increase of the LAGBs percentage $(\rho(25 \mathrm{~mm})<$ $\rho(65 \mathrm{~mm})<\rho(120 \mathrm{~mm}))$. Meanwhile, the effect of LAGBs should be considered and the formula is [34]:

$$
\Delta \sigma_{\mathrm{gb}} \cong \alpha_{2} \mathrm{~GB}\left(1-f_{\text {rex }}\right)\left(\frac{1}{\delta}\right),
$$

where $f_{\text {rex }}$ represents the recrystallization fraction and $\delta$ represents the subcrystalline size.

In conclusion, different factors affect the yield strength to different degrees. When stretched along the RD, $\mu(25 \mathrm{~mm}) \approx \mu(65 \mathrm{~mm})>\mu(120 \mathrm{~mm})$ as shown in Table 4 . In general, the value of $M$ is inversely proportional to the value of $\mu$. Thus, $M(25 \mathrm{~mm}) \approx \mathrm{M}(65 \mathrm{~mm})<$ $\mathrm{M}(120 \mathrm{~mm})$. For the value of $\sigma_{\mathrm{ss}}, \tau(25 \mathrm{~mm})<\tau(65 \mathrm{~mm})<\tau(120 \mathrm{~mm})$, so $\sigma_{\mathrm{ss}}(25 \mathrm{~mm})<$ $\sigma_{\mathrm{ss}}(65 \mathrm{~mm})<\sigma_{\mathrm{ss}}(120 \mathrm{~mm})$. For the value of $\sigma_{\mathrm{gs}}, \sigma_{\mathrm{gs}}(25 \mathrm{~mm})>\sigma_{\mathrm{gs}}(65 \mathrm{~mm})>\sigma_{\mathrm{gs}}(120 \mathrm{~mm})$. For the value of $\sigma_{\mathrm{d}}, \sigma_{\mathrm{d}}(25 \mathrm{~mm})<\sigma_{\mathrm{d}}(65 \mathrm{~mm})<\sigma_{\mathrm{d}}(120 \mathrm{~mm})$. The degree of recrystallization fraction and the subcrystalline size are smaller for the $25 \mathrm{~mm}$ plate, so $\Delta \sigma_{\mathrm{gb}}(25 \mathrm{~mm})>$ $\Delta \sigma_{\mathrm{gb}}(65 \mathrm{~mm})>\Delta \sigma_{\mathrm{gb}}(120 \mathrm{~mm})$. As shown in Figure 12, $\sigma_{0 \cdot 2}(25 \mathrm{~mm})>\sigma_{0 \cdot 2}(65 \mathrm{~mm})>$ $\sigma_{0} \cdot 2(120 \mathrm{~mm})$; the mechanical results above indicate that the strengthening effect of grain boundaries (including LAGBs) plays more significant roles in the strengthening of $\sigma_{0 \cdot 2}$ than the effect of the solid atoms and dislocation density. Thus, decreasing the degree of recrystallization and grain growth (increasing the percentage of the grain boundaries and low-angle grain boundaries) are the main methods to improve the yield strength.

In this work, the evolution of textures, the degree of recrystallization and mechanical properties during the process of re-dissolution of different plates were discussed. The slip systems that may be actuated and the factors that affect the yield strength in different degrees of different plates were also analyzed. Meanwhile, the phenomenon that the high orientation density of Brass texture caused the elongation after fracture to decrease rapidly was seldom reported by other reviewers. This work will provide many ideas for other researchers. For example, in order to enhance the mechanical properties of the plates, the optimal solution time is the moment when the redissolution process is mainly completed. Considering the intrinsic influence of different strengthening methods, increasing the strengthening effects of the grain boundaries (including LAGBs) is an effective means to improve the mechanical properties. However, there are additional factors affecting the mechanical properties and formability. First, although the aging temperature is low in this study and textures are assumed unchanged in the aging treatment, texture changes may be influenced by the aging time. Meanwhile, different deformation may affect texture changes to different degrees during aging treatments. Secondly, since the plates investigated are all rather thick, localized thinning may not be a problem during processing. Therefore, in order to solve localized thinning problems, texture evolution trends for thin plates (thickness less than $6 \mathrm{~mm}$ ) during solution and aging treatments need to be investigated in the future.

\section{Conclusions}

(1) Different plates exhibit different processes of re-dissolution. For the $25 \mathrm{~mm}$ and $120 \mathrm{~mm}$ plates, the re-dissolution is almost completed in $90 \mathrm{~min}$ at $477^{\circ} \mathrm{C}$. However, the re-dissolution time of the $65 \mathrm{~mm}$ plates is shorter $(30 \mathrm{~min})$ compared with the other plates at the same temperature.

(2) The $25 \mathrm{~mm}$ and $65 \mathrm{~mm}$ plates exhibit significant fiber textures along the RD and TD, while the fiber texture is not obvious for the $120 \mathrm{~mm}$ plate along the TD. The value of 
$\mu$ along the $\mathrm{RD}$ is significantly larger than that along the TD, which leads to a lower yield strength along the RD.

(3) With the increase of deformation and static recrystallization degrees, texture types change from Cube, R-Cube to Brass, R, Cube and Copper during the re-dissolution process. After the dissolution of the second phase, the orientation density of Brass texture first increases and then decreases in the three plates. With the maximum of the Brass orientation density, the elongation after fracture decreases sharply to $\sim 1.4 \%$.

(4) In terms of the contribution of the yield strength, grain boundary strengthening including LAGBs plays more significant roles than the effect of solid atoms and dislocation densities. The $25 \mathrm{~mm}$ plate exhibits the best mechanical properties, with a yield strength of $565.7 \mathrm{MPa}$ along the rolling direction.

Author Contributions: Conceptualization, L.J. and H.Z.; methodology, L.J. and H.Z.; formal analysis, H.W. and L.J.; resources, C.L. and X.Z.; writing-original draft preparation, H.W.; writing-review and editing, W.W., C.Y. and L.J.; funding acquisition, C.L. and H.Z. All authors have read and agreed to the published version of the manuscript.

Funding: The project received financial support, and the project number is: JZKG20190099.

Data Availability Statement: The datasets generated during and/or analyzed during the current study are available from the corresponding author on reasonable request.

Conflicts of Interest: On behalf of all authors, the corresponding author states that there is no conflict of interest.

\section{Nomenclature}

B Burgers vector

BC boundary contrast

DCAP dissimilar channel angular pressing

EDS energy dispersive spectroscopy

G shear modulus

HAGBs high angle grain boundaries

IPF inverse pole figure

LAGBs low-angle grain boundaries

M Taylor factor

ND normal direction

ODF orientation distribution function

OM optical microscopy

RD rolling direction

SEM scanning electron microscope

TD transverse direction

XRD X-ray diffraction

$\mu \quad$ Schmid factor

$\mu \quad$ average value of $\mu$

$\sigma_{0} \quad$ yield strength of pure Al matrix

$\sigma_{\mathrm{ss}} \quad$ strength affected by the solid solution

$\sigma_{\mathrm{gs}} \quad$ strengthening effect of grain boundaries

$\sigma_{\mathrm{d}} \quad$ strength affected by the dislocation density

$\tau \quad$ strength contribution caused by the solute atoms

$\rho \quad$ dislocation density

$\mathrm{F}_{\text {rex }} \quad$ recrystallization fraction

$\delta \quad$ subcrystalline size

$\Delta \sigma_{\mathrm{gb}} \quad$ effect of LAGBs 


\section{References}

1. Czerwinski, F. Thermal Stability of Aluminum Alloys. Materials 2020, 13, 3441. [CrossRef] [PubMed]

2. Peng, H.; Chen, C.; Ren, X.; Wu, J. Development of clinching process for various materials. Int. J. Adv. Manuf. Technol. 2021, 1-19. [CrossRef]

3. Fan, X.; Li, Y.; Xu, C.; Wang, B.; Peng, R.; Chen, J. Improved mechanical anisotropy and texture optimization of a 3xx alu-minum alloy by differential temperature rolling. Mater. Sci. Eng. A 2021, 799, 140278. [CrossRef]

4. $\quad$ Li, Y.; Xu, G.; Liu, S.; Wang, B.; Peng, X. Study on anisotropy of Al-Zn-Mg-Sc-Zr alloy sheet. Mater. Charact. 2021, $172,110904$. [CrossRef]

5. She, X.-W.; Jiang, X.-Q.; Wang, P.-Q.; Tang, B.-B.; Chen, K.; Liu, Y.-J.; Cao, W.-N. Relationship between microstructure and mechanical properties of 5083 aluminum alloy thick plate. Trans. Nonferrous Met. Soc. China 2020, 30, 1780-1789. [CrossRef]

6. Zang, Q.; Feng, D.; Lee, Y.-S.; Chen, H.; Kim, M.-S.; Kim, H.-W. Microstructure and mechanical properties of Al-7.9Zn-2.7Mg-2.0Cu $(\mathrm{wt} \%)$ alloy strip fabricated by twin roll casting and hot rolling. J. Alloy. Compd. 2020, 847, 156481. [CrossRef]

7. Jia, L.; Ren, X.; Hou, H.; Zhang, Y. Microstructural evolution and superplastic deformation mechanisms of as-rolled 2A97 alloy at low-temperature. Mater. Sci. Eng. A 2019, 759, 19-29. [CrossRef]

8. Li, S.; Zhao, Q.; Liu, Z.; Li, F. A Review of Texture Evolution Mechanisms During Deformation by Rolling in Aluminum Alloys. J. Mater. Eng. Perform. 2018, 27, 3350-3373. [CrossRef]

9. Nam, S.K.; Lee, J.-H.; Kim, G.-H.; Lee, D.N.; Kim, I. Texture Analysis for Enhancement of R-value in Asymmetrically Rolled Al Alloy Sheet. J. Mater. Eng. Perform. 2019, 28, 5186-5194. [CrossRef]

10. Shen, F.; Zhou, Z.; Li, W.; Sun, Z.; Tian, J.; Xie, C.; Guo, J.; Liao, Z.; Yi, D.; Zhang, J.; et al. Mi-cro-mechanism of texture evolution during isochronal annealing of as-annealed hot rolled Al-Cu-Mg sheet. Mater. Des. 2019, 165, 107575. [CrossRef]

11. Venkatachalam, P.; Roy, S.; Ravisankar, B.; Paul, V.T.; Vijayalakshmi, M.; Suwas, S. Texture evolution in an Al-Cu alloy during equal channel angular pressing: The effect of starting microstructure. J. Mater. Sci. 2011, 46, 6518-6527. [CrossRef]

12. Deng, Y.-L.; Wan, L.; Zhang, Y.; Zhang, X.-M. Evolution of microstructures and textures of 7050 Al alloy hot-rolled plate during staged solution heat-treatments. J. Alloy. Compd. 2010, 498, 88-94. [CrossRef]

13. Xu, X.; Mao, Q.; Jiang, Z.; Vitus, T.; Zhang, T.; Jia, W.; Zhu, C.; Wang, H. Effect of multi-stage solution and aging process on mi-crostructure and properties of Al-11.2Zn-3.0Mg-1.3Cu-0.2Zr aluminum alloy extrusion. Mater. Lett. 2019, 254, 375-378. [CrossRef]

14. Zhang, K.; He, Q.; Rao, J.H.; Wang, Y.; Zhang, R.; Yuan, X.; Feng, W.; Huang, A. Correlation of textures and hemming performance of an AA6XXX aluminium alloy. J. Alloy. Compd. 2021, 853, 157081. [CrossRef]

15. Khan, M.A.; Wang, Y.; Cheng, H.; Yasin, G.; Malik, A.; Nazeer, F.; Ahmad, T.; Khan, W.Q.; Kamran, M.; Afifi, M.A. Microstructure evolution of an artificially aged Al-Zn-Mg-Cu alloy subjected to soft- and hard-steel core projectiles. J. Mater. Res. Technol. 2020, 9, 11980-11992. [CrossRef]

16. Wang, X.; Guo, M.; Cao, L.; Luo, J.; Zhang, J.; Zhuang, L. Effect of heating rate on mechanical property, microstructure and texture evolution of Al-Mg-Si-Cu alloy during solution treatment. Mater. Sci. Eng. A 2015, 621, 8-17. [CrossRef]

17. Zuiko, I.; Mironov, S.; Kaibyshev, R. Microstructural evolution and strengthening mechanisms operating during cryogenic rolling of solutionized Al-Cu-Mg alloy. Mater. Sci. Eng. A 2019, 745, 82-89. [CrossRef]

18. Moghanaki, S.K.; Kazeminezhad, M.; Logé, R. Mechanical behavior and texture development of over-aged and solution treated Al-Cu-Mg alloy during multi-directional forging. Mater. Charact. 2018, 135, 221-227. [CrossRef]

19. Tang, J.; Wang, J.; Teng, J.; Wang, G.; Fu, D.; Zhang, H.; Jiang, F. Effect of Zn content on the dynamic softening of Al-Zn-Mg-Cu alloys during hot compression deformation. Vacuum 2021, 184, 109941. [CrossRef]

20. Suo, C.; Ma, P.; Jia, Y.; Liu, X.; Shi, X.; Yu, Z.; Prashanth, K. Annealing of Al-Zn-Mg-Cu Alloy at High Pressures: Evolution of Microstructure and the Corrosion Behavior. Materials 2021, 14, 2076. [CrossRef] [PubMed]

21. Chae, W.; Kim, B.-K.; Lee, J.; Han, J.H. Effects of Initial Precipitate on Shear Deformation during Asymmetric Rolling of Al-Mg-Si Alloy: Texture and Formability. Korean J. Met. Mater. 2020, 58, 703-714. [CrossRef]

22. Mei, L.; Chen, X.; Ren, P.; Nie, Y.; Huang, G.; Liu, Q. Effect of warm deformation on precipitation and mechanical properties of a cryorolled Al-Zn-Mg-Cu sheet. Mater. Sci. Eng. A 2020, 771, 138608. [CrossRef]

23. Poole, W.; Wang, X.; Embury, J.; Lloyd, D. The effect of manganese on the microstructure and tensile response of an Al-Mg-Si alloy. Mater. Sci. Eng. A 2019, 755, 307-317. [CrossRef]

24. Sadeghi, A.; Kyokuta, N.; Inoue, J.; Koseki, T. Effect of initial texture and microstructure of Mg on mechanical properties of $\mathrm{Mg}$-Stainless steel laminated metal composites. Mater. Charact. 2017, 127, 171-178. [CrossRef]

25. Han, J.-H.; Huh, M.; Suh, J.-Y.; Lee, J.-C. Controlling the textures of the Al alloy sheet via dissimilar channel angular pressing. Mater. Sci. Eng. A 2005, 394, 60-65. [CrossRef]

26. Wang, L.; Yang, X.; Robson, J.D.; Sanders, R.E.; Liu, Q. Microstructural Evolution of Cold-Rolled AA7075 Sheet during Solution Treatment. Materials 2020, 13, 2734. [CrossRef]

27. Feng, S.; Sun, L.M.; Chen, Z.G.; Zheng, Z.Q.; Li, J.F. Microstructure and mechanical properties of 7056 aluminum alloy thick plates. Rare Met. Mater. Eng. 2018, 47, 3088-3095. (In Chinese)

28. Li, P.; Ding, C.; Wang, B.; Wu, G.; Xue, K. Dissolution of secondary phase in novel Al-Zn-Mg-Cu alloy reduced by high pressure torsion. Chin. J. Nonferrous Met. 2019, 29, 11-17. (In Chinese)

29. Shackelford, J.F. Introduction to Materials Science for Engineers, 3rd ed.; Mcmillan Pub Co: New York, NY, USA, 1992. 
30. Yang, G.; Chen, L.; Wang, J.; Wang, J.; Shi, Q. Influences of Texture of FCC Metals on Their Mechanical Properties. J. Kunming Univ. Sci. Technol. 2012, 37, 24-27.

31. Zhang, P.; Li, Y.; Liu, Y.; Zhang, Y.; Liu, J. Analysis of the microhardness, mechanical properties and electrical conductivity of 7055 aluminum alloy. Vacuum 2020, 171, 109005. [CrossRef]

32. Hu, Z.; Zhang, H.; Zhu, H.; Xiao, Z.; Nie, X.; Zeng, X. Microstructure, mechanical properties and strengthening mechanisms of AlCu5MnCdVA aluminum alloy fabricated by selective laser melting. Mater. Sci. Eng. A 2019, 759, 154-166. [CrossRef]

33. Chen, Z.G.; Ren, J.K.; Yuan, Z.G.; Ringer, S.P. Enhanced strength-plasticity combination in an Al-Cu-Mg alloy-Atomic scale microstructure regulation and strengthening mechanisms. Mater. Sci. Eng. A 2020, 787, 139447. [CrossRef]

34. Ma, K.K.; Hu, T.; Yang, H.; Topping, T.; Yousefiani, A.; Lavernia, E.J.; Schoenung, J.M. Coupling of dislocations and precipitates: Impact on the mechanical behavior of ultrafine grained Al-Zn-Mg alloys. Acta Mater. 2016, 103, 153-164. [CrossRef] 